\title{
Performance Psychology Case Study of Elite Show Jumper
}

\author{
Cíara Losty* \\ Lecturer in Applied Sport and Exercise Psychology, Waterford Institute of Technology, Ireland \\ *Corresponding author: Cíara Losty, Lecturer in Applied Sport and Exercise Psychology, Waterford Institute of Technology, Ireland

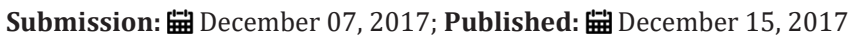

\section{Personal Philosophy}

My philosophy is that when working with athletes and their coaches my role is to educate, facilitate, inspire, empower. The goal of our interactions is to ensure that ultimately an athlete can consistently demonstrate the psychological skills necessary for optimum performance. The work I do is always centred on the athlete, their needs are paramount. I believe strongly that ultimately my role as a sports psychologist is to create an environment of selfempowerment, where the athlete takes personal responsibility and control for their sporting destiny.

\section{Explanation of the Performance Issue}

Jack was a 31 year old elite show-jumper who contacted me because he felt that he was not achieving his potential at the big international competitions and he thought that sport psychology could help him begin to produce the consistent performances that he knew he was capable of.. The initial information gathering and familiarisation took the format of a semi-structured interview, similar to that recommended by Weinberg \& Williams [1]. During this process among other things I asked Jack to outline his time so far in the show-jumping world; to give me a picture of his week from start to finish-both in and out of sport; to describe two of his strengths and two weaknesses; to state his goals for the coming season and for the longer term; and to describe in detail anything he was currently having a problem with Jack felt that he was investing huge amounts of his time, effort, energy and indeed money into this sport, and the issue for him was how to maximise the output so that he was doing himself and his horse's justice on the international stage, something that was eluding him at present.

\section{Underpinning Technical/Theoretical Rationale for Intervention}

During his initial consultation session Jack described several behaviours and practices that seemed to my mind to be contributing to his current state of fatigue, tension, and irritability, and these in turn would impact on his ability to relax and focus while riding his horses. I wondered at his thought processes when it came to these behaviours-did he ever actually think about some of the decisions he was making, did he consider at all if they were smart choices?
There were many performance lifestyle issues contributing to Jack arriving at a situation whereby when he sat up on a horse to go into the ring to compete, he was tired, tense and focused on everything but the task at hand. Bell [2] makes an excellent point when discussing thinking what is important is not so much whether a thought is right or wrong, but more pertinent is whether a thought is helpful when it comes to an athlete achieving their goals. My feeling was that in Jack's case his thinking in relation to a few issues was not helpful but he had failed to recognise this, and so his unhelpful thinking had led to unhelpful behaviours ones that were bringing him further away from his goals instead of taking him to them. The primary interventions used here were Countering to help Jack learn to use reason to challenge un-helpful thinking, and Reframing to help Jack find new and thus more helpful ways of looking at things, both being effective ways of changing thoughts and beliefs [3]. This in turn would lead to him developing more helpful behaviours and practices.

\section{Intervention Package}

\section{Countering \& reframing}

From talking to Jack at length it emerged that some of the decisions he made about how to run his yard were made based on beliefs that were in fact neither accurate nor helpful. Incorporating a format similar to Steinmetz, Blankenship \& Brown's (1980) five criteria for determining if underlying beliefs are productive and rational, I worked with Jack on the beliefs above until he began to really think about them. Using Countering as a strategy I got Jack to challenge these beliefs, to test them out rather than blindly accepting them. Jack quickly began to realise that these beliefs were limiting, un-helpful, and were in fact hindering him. So over time we used Reframing as a strategy to identify more useful and accurate thought processes around these issues. Jack began to see that there were other ways of looking at things, and indeed other ways of running his business.

\section{Stress management}

In order to get the best from his horse and from himself, Jack needed to gain control over the tension that was taking hold of 
him at competition venues. Whilst we previously identified that a good deal of this tension had built up because of a combination of poor planning and poor nutrition issues, it was also evident that Jack could benefit from developing skills for managing stress and tension.

\section{Phase one}

With this in mind, we went through an education phase whereby I taught Jack about the concept of stress so that he understood what exactly happens when the stress/tension/anxiety reaction occurs, we identified his triggers for stress, we looked at his own reactions to stress, and the consequences of when stress and tension over powered him. The most interesting thing to emerge from these discussions with Jack was that for him the competition itself was never a stressor; he felt excited but confident about his actually performance, with a few nerves slipping in when he got into a jump off against the clock. Instead the greatest source of stress for Jack was the feeling of rushing, of having no time to sit and think about how he would ride this horse as opposed to the last one, of worrying if his next horse would be ready for him to go into the practice arena when he had finished on this horse [4].

\section{Phase two}

The next phase of this intervention was to introduce the psychological skills for coping with stress. The first of these skills was actually dealt with in the first intervention as described above, in that through Countering and Reframing Jack learned to develop useful thinking, planning and behaviour specifically in terms of sharing the workload and looking after him by taking time for meals and eating the right food. A second skill that I used to help Jack feel calm when it came to riding each horse was the introduction of a pre-round time out. This would take the place of the frantic racing around that usually preceded Jack sitting up on a horse to go and jump. During this ten minute time slot Jack agreed that he would go to a quiet place, possibly the cab of the lorry, and he would sit quietly and mentally prepare to ride the next horse in the next round. Giving himself this time to clear his mind of irrelevant thoughts, to think about the job at hand, and to re-group energy wise, allowed Jack to get himself into the right frame of mind before he sat up on each and every horse. He felt that this would give him the chance to do justice in each round, as now he would have his full mind on the job rather than half his mind being somewhere else.

The third skill that I taught Jack during this phase was the skill of relaxation. Having explored several options, Jack showed a preference for the Centering technique, one of many strategies used for quickly regaining control during competition [5]. The reason that he liked this exercise so much was that it was quick to master and once mastered it was effective in an instant, but also it served as a relaxation tool to lower excess tension in his body, and as a tool to refocus attention, so it was dual purpose.

\section{Phase three}

The third phase of the intervention was the practice phase, whereby with monitoring Jack moved from practising Centering sitting quietly in a chair at home, to sitting on a hay bale in the stable yard, to sitting watching a round at a noisy show, right up until he was able to centre as he sat on his horse.

\section{Phase four}

The fourth phase of the intervention was the evaluation phase, when each of the tools designed to help Jack manage stress and tension were assessed in terms of their effectiveness [6]. For this purpose I used a scale of $0-10$, with 0 being 'not working at all' and 10 being 'working really well', and Jack used the scale to assess his perception of the effectiveness of the skills he had learned. Over time modifications were made until the ratings for each skill (helpful thinking \& planning, pre-round time out, and Centering) improved and ultimately Jack reported feeling fully in control and able to be calm when he sat up on a horse before competition.

The effectiveness of the overall programme was assessed by using the concept of Butler and Hardy's Performance Profile (1992) to gauge Jack's feeling about where he lay in relation to the skills needed for success in his sport [7].

\section{Resultant Performance Impact}

Jack won three Grand Prix competitions on the international circuit the same year that we worked together and his wins on the domestic circuit increased. He reported having much more consistent performances, with more clear rounds and more wins in jump offs. He often had not one or even two, but up to three horses with double clears in one competition. He had not yet made a Nations Cup team but he knew now that he was giving himself the absolute best chance to be considered for one.

\section{References}

1. Weinberg RS, Williams JM (2001) Integrating and implementing a psychological skills training programme. In: Williams J (Ed.), Applied Sport Psychology, Personal Growth to Peak Performance. McGraw-Hill, New York, USA, pp. 425-457.

2. Bell KE (1983) Championship thinking: The athlete's guide to winning performances in all sports. Englewood Cliffs, Prentice-Hall, USA.

3. Zinsser N, Bunker L, Williams JM (2001) Cognitive techniques for building confidence and enhancing performance. In: Williams J (Ed.), Applied Sport Psychology, Personal Growth to Peak Performance. McGraw-Hill, New York, USA, pp. 349-381.

4. Nideffer RM (1992) Psyched to Win. Champaign, Leisure Press, Illinois, USA.

5. Butler RJ, Hardy L (1992) The Performance Profile: Theory and Application. The Sport Psychologist 6(3): 253-264.

6. McBane S (1987) Behaviour Problems in Horses. Understanding Nervousness in Horse and Rider, JA Allen, London, UK.

7. Spielberger CS (1966) Theory and research on anxiety. Academic Press, New York, USA, pp. 3-20. 